\title{
Focus in Relative Clause Construal
}

\author{
Amy Schafer, Juli Carter, Charles Clifton Jr and Lyn Frazier \\ University of Massachusetts, Amherst, Massachusetts, USA
}

Two auditory comprehension studies investigated the role of focus, as conveyed by a pitch accent, in the comprehension of relative clauses preceded by a complex NP (e.g. the propeller of the plane that...). In the first experiment, accenting $\mathrm{N}_{1}$ (propeller) or $\mathrm{N}_{2}$ (plane) increased the probability that the accented NP would be taken as head of the relative clause. This supported the predictions of a Focus Attraction Hypothesis as applied to relative clauses. The second experiment manipulated the prosodic status of the relative clause (accented or unaccented) as well as the type of accent on a potential head of the relative clause. It demonstrated that focus on a potential head of a relative clause attracts both accented relative clauses, presumed to convey new information, and unaccented relative clauses, presumed to convey given information. This supported a straightforward version of the Focus Attraction Hypothesis as opposed to a Congruence Hypothesis, which claims that only modifiers marked as conveying new information preferentially are related to other phrases that are marked as new. The experiment also demonstrated that a contrastive accent on a potential head of a relative clause attracts relative clauses even more than a focal accent that is appropriate for new information.

\section{INTRODUCTION}

Our understanding of sentence processing has increased rapidly in the last two decades. Many of the basic principles underlying syntactic analysis have been mapped out, and a variety of models of sentence processing now exist (e.g. Fodor \& Inoue, 1994; Frazier, 1979; Gibson, 1991; MacDonald, Pearlmutter, \& Seidenberg, 1994; Mitchell, 1994; Pritchett, 1992). Much of the empirical work in psycholinguistics has been based on studies of written language, which preserves only a limited amount of prosodic information

Requests for reprints should be addressed to Charles Clifton Jr, Department of Psychology, University of Massachusetts, Amherst, MA 01003-7710, USA.

We are grateful to Lisa Selkirk for discussion of the issues taken up here and for listening to the experimental sentences. Thanks are also due to Richard Gobeil for undertaking the acoustic analyses, to Stacy Birch for conducting the ToBI analyses, and to Ann Cloutier for testing many subjects. This research was supported in part by Grants HD-18708 and HD-07327 from the NIH. Juli Carter is now at the Department of Linguistics, University of California at San Diego.

(C) 1996 Psychology Press, an imprint of Erlbaum (UK) Taylor \& Francis Ltd 
(e.g. in the form of commas typically marking prosodic breaks at major constituent boundaries).

Studies of auditory sentence processing have demonstrated that prosodic information may bias or fully disambiguate the syntactic structure of an input sentence. For the most part (though see Broderick, 1995; Nagel, Shapiro, \& Nawy, 1994), prosodic disambiguation is accomplished in cases where there is correspondence between breaks in the syntactic structure and breaks in the prosodic structure (Beach, 1991; Lehiste, 1973; Nespor \& Vogel, 1986; Price, Ostendorf, Shattuck-Hufnagel, \& Fong, 1991; Slowiaczek, 1981; Wales \& Toner, 1979; Warren, 1985).

The major concern in the present paper is whether intonation and prosody may also influence a perceiver's choice of a sentence structure in cases where a pitch accent may be used to convey focus. Specifically, we report two experiments designed to test the idea that placing a pitch accent on a particular noun will serve to attract an optional modifier, in the present case a relative clause. In sentences where either of two NPs may head the relative clause, placement of a pitch accent on a noun can focus the NP headed by that noun, increasing the likelihood of the perceiver's attaching the relative clause to that NP. The basic hypothesis is given in (1): ${ }^{1}$

1. Focus Attraction Hypothesis: It is more likely that a phrase that is neither a complement nor syntactically obligatory will be taken to modify a phrase $\mathrm{P}$ if $\mathrm{P}$ is focused than if it is not, grammatical and pragmatic constraints permitting.

Focus may in general reflect the importance of information to a listener (see Cutler \& Fodor, 1979; Cutler \& Foss, 1977). We suspect that perceivers may abide by the Focus Attraction Hypothesis in (1) precisely because this allows a phrase (e.g. relative clause) to be related to important information in the sentence. However, accent does not only mark focused and important information in the sentence. New information must also be accented. This raises the possibility that it is not focus but the ("given/new") information status of two phrases that underlies the effect predicted by the Focus Attraction Hypothesis. In other words, perceivers confronted with a relative clause prosodically marked as new information may opt for the relative

\footnotetext{
${ }^{1}$ We have developed this hypothesis in the framework of construal (Frazier \& Clifton, 1995), where no initial syntactic preference should govern initial attachment in the cases studied here. In this framework, a relative clause will simply associate to the current thematic processing domain. As demonstrated by Gilboy et al. (1995), a variety of factors including referentiality of the NPs, thematic domain structure, plausibility and Gricean communicative constraints influence the final choice of a head for a relative clause. The Focus Attraction Hypothesis adds one more factor to this list.
} 
clause to modify a head noun also marked as new. We dub this the Congruence Hypothesis, stated in (2):

2. Congruence Hypothesis: A modifier marked as conveying new information preferentially is related to another phrase also marked as new (and a modifier marked as conveying given information is preferentially related to another phrase also marked as given).

Experiments 1 and 2 test the predictions of the basic Focus Attraction Hypothesis. Experiment 2 also tests the Congruence Hypothesis by manipulating the presence of an accent on the relative clause and the kind of accent (new $v s$ contrastive and possibly old) on a potential head of the relative clause. Before describing the experiments, however, we will take up our background assumptions about the theory of intonation and the grammar of focus, and then provide a sketch of existing studies of the role of prosody in sentence processing.

\section{Intonation Theory and the Grammar of Focus}

We adopt the basic intonational theory of Beckman and Pierrehumbert (1986; cf. Pierrehumbert, 1980), who argue that each utterance must be divided into one or more "intonational phrases" (IP), which are in turn divided exhaustively into "intermediate phrases" (ip). Each intermediate phrase must contain a phrase accent (L-, H-), preceded by one or more pitch accents (e.g. $\mathrm{H}^{*}, \mathrm{~L}^{*}, \mathrm{~L}+\mathrm{H}^{*}$ ) (at least in intonational phrases other than vocatives; see Gussenhoven \& Rietveld, 1992). An intonational phrase must also include a boundary tone $(\mathrm{L} \%, \mathrm{H} \%)$. Boundaries of various strengths (0-6) may occur at word boundaries, with stronger boundaries or breaks (4 and above, in the notation used by Beckman \& Pierrehumbert; see also Beckman \& Ayers, 1993) typically being realised as lengthening of the final accented syllable preceding the boundary and a pause preceding the next word (see Wightman, Shattuck-Hufnagel, Ostendorf, \& Price, 1992, for empirical support). Finally, in Beckman and Pierrehumbert's system, the detailed intonation of a sentence results from a phonetic interpolation which smooths the transition from the pitch values assigned to the individual pitch accents in the sentence.

We adopt the basics of Selkirk's $(1984,1995)$ theory of focus and the syntax-prosody interface. Selkirk argues that each pitch accent introduces an "F-marking" into the syntactic representation of the sentence. According to her "basic focus rule", each word bearing a pitch accent is F-marked in the syntactic representation. By the "rule of focus projection", a phrase may be F-marked if its head is F-marked. Also, the head of the phrase may be 
F-marked if one of its internal arguments is F-marked. On this model, it is the F-marking in the syntactic representation that is semantically interpreted, not the pitch accent directly. An F-marked constituent may be interpreted as new in context or as contrastive. A phrase which is not F-marked must be interpreted as being already given in context.

\section{Previous Research on Prosodic Disambiguation}

Experimental studies of auditory and visual language processing (Cutler \& Fodor, 1979; Cutler \& Foss, 1977; Hornby, 1972, 1974) have suggested that perceivers devote more attention to processing focused material than to processing unfocused material. The similarity of the effects when focus is conveyed by the presence of a pitch accent and when it is conveyed by some other means (e.g. by the required focus on a questioned constituent in a question-answer pair) supports the idea that the influence of pitch accents is not direct but mediated through the assignment of focus, as one would expect given a theory like Selkirk's. Several studies have also demonstrated the importance of contextually appropriate accentuation of utterances (Bock \& Mazella, 1983; Eady et al., 1986; Eefting, 1992). New information must be accented, and old information may be accented only if it is contrastive or if the speaker is using an emphatic style.

A number of studies have shown that boundaries play a role in syntactic ambiguity resolution. Lehiste (1973), for example, found that listeners performed at above chance levels in identifying the intended analysis of 10 of the 15 types of ambiguity she studied. The most easily disambiguated sentences included sentences like (3) and (4), where a prosodic break can indicate intended constituency. These may be compared with (5) and (6), where the ambiguity does not involve grouping into syntactic constituents and prosodic disambiguation was not observed. Lehiste suggested that the largest effect might be due to lengthening of the interval between stresses where there would be a syntactic boundary on one analysis but not the other.

3. The old men and women stayed at home.

4. Steve or Sam and Bob will come.

5. Visiting relatives can be a nuisance.

6. The shooting of the hunters was terrible.

Nespor and Vogel (1986) formulate a closely related hypothesis, casting it in terms of prosodic phonology. They define a phonological phrase as a clitic group $(c)$, which contains a lexical head $(X)$ and all $c$ 's on its non-recursive side up to the $c$ that contains another head outside the maximal projection of $X$. In a language like English, which is right-branching, this essentially 
groups together the clitic group containing the lexical head of a phrase and all preceding material in the same maximal projection. An intonational phrase may group together adjacent phonological phrases in the root sentence, or any phonological phrase not structurally attached to the tree (e.g. parentheticals). Nespor and Vogel's prosodic hypothesis claims that when both the phonological and intonational phrases are the same for two interpretations of a sentence, the sentence cannot be prosodically disambiguated.

Nespor and Vogel present data supporting the idea that sentences which differ in their placement of a syntactic boundary can be disambiguated if they differ in the placement of an intonational phrase boundary. For example, a native speaker of Italian could readily disambiguate the Italian counterpart to the sentences in (7-9):

7a. When Fifi attacks her, growling can be heard a block away.

b. When Fifi attacks, her growling can be heard a block away.

8a. The lawyer spoke, naturally.

b. The lawyer spoke naturally.

9a. Those people smoked everywhere.

b. Those, people smoked everywhere.

Price et al. (1991) tested seven structural types of ambiguities. They too argued that disambiguation depends on the type of ambiguity, and that disambiguation is primarily due to boundary phenomena. They concluded: "By and large, relatively large break indices tended to mean that syntactic attachment was higher rather than lower. In contrast to the pervasive association of boundary cues with successful disambiguation, prominence seemed to play mainly a supporting role and was the sole cue in only a few sentences" (p. 2963). Overall, their subjects were $85 \%$ correct (or above) at identifying the intended structure for the sentences in (10)-(13):

10. Parentheticals: Mary knows many languages (,) you know.

11. Apposition: The neighbors who usually read (,) the Dalies, were amused.

12. Tags: Dave will never know why he's enraged (,) will he? (Willy)

13. Left vs right attachment: They rose early (,) in May.

Prosodic boundaries are typically signalled by pre-boundary lengthening, by a steeper fall in pitch before the boundary, and by a sharper rise in pitch after the boundary compared to the no-boundary case (Beach, 1991; Cooper \& Sorensen, 1981; Klatt, 1975; Lehiste, 1973; Warren, 1985; and references therein). The presence of a boundary, whether signalled by a pause, lengthening, or F0 changes, also seems intuitively to disambiguate the 
attachment of a relative clause. Given "the daughter of the colonel who...", the presence of a major boundary after colonel intuitively biases the analysis of the relative clause, favouring a high attachment in which the relative clause modifies the entire complex NP.

In general, not just in relative clause attachment ambiguities, the presence of a major boundary favours high attachment of the phrase following the boundary; for example, high attachment of the NP the sock in (14a), high attachment of naturally in (14b), high attachment of and Bob in (14c), etc.:

14a. While Mary was mending the sock...,

b. My uncle Abraham gave his talk naturally...

c. Steve or Sam and Bob...

In other words, given two analyses of a string which differ only in the position of one right bracket (at position $\mathrm{M}$ or a later position $\mathrm{N}$ ), the presence of a major boundary at $\mathrm{M}$ favours the analysis where the ambiguous syntactic bracket occurs at position $\mathbf{M}$, thereby terminating the lowest constituent of the current phrase and typically inviting or forcing high attachment of the following phrase. This observation is in line with the proposals of Lehiste (1973, 1974), Nespor and Vogel (1986) and Price et al. (1991), and accounts for the major findings in those studies. We will return to this observation in the discussion of the results of Experiment 2.

Prosodically specified focus, on the other hand, has not been claimed to play a role in syntactic disambiguation of sentences. Indeed, Price et al. (1991) have suggested that it does not play a central role. Experimental studies have rarely looked for an effect of pitch accent placement on syntactic disambiguation. One exception comes from Speer, Crowder and Thomas (1993), who showed that manipulations of focus, as in (15a) versus (15b), as well as manipulations of prosodic boundary placement, as in (16a) versus (16b), do result in different interpretations in a forced-choice disambiguation task:

15a. They are FRYING chickens.

b. They are frying CHICKENS.

16a. The dog may attack Gwen.

b. The dog may attack, Gwen.

However, placing accent on frying versus chickens may affect the prosodic phrasing of sentences like those used by Speer et al., as well as affecting their focus (or "given/new") structure. Thus, it is possible that this apparent demonstration that focus affects syntactic analysis may actually be another demonstration that prosodic phrasing does so. 
Models of the Role of Prosody and Intonation in Sentence Processing

Marcus and Hindle (1990) present a model of processing which exploits the presence of major intonational boundaries (intonational phrase boundaries). When a major boundary is identified in the input, a new constituent is constructed rather than directly incorporating the new item into the current syntactic phrase. The new constituent can later be attached within the syntactic phrase marker, using other prosodic cues such as pitch ranges, minor boundaries and pitch accents to join the pieces together in a coherent fashion. If the boundary dividing the new constituent from previous material is obligatory (by virtue of its syntactic position), it will constrain later attachment of the constituent and disambiguate the sentence. Optional boundaries, on the other hand, occur at points where Marcus and Hindle's D-theory model permits attachment regardless of the presence of the boundary, and thus do not syntactically disambiguate sentences. Marcus and Hindle's model is important in offering an explicit account of the integration of prosodic and syntactic information, but may be too conservative in its reliance on only major intonation boundaries as the exclusive contribution of prosody to initial parsing decisions.

An alternative to Marcus and Hindle's model claims that what the syntactic processor parses is a full prosodic representation of the sentence (cf. Ferreira, 1993, for evidence from sentence production). Unlike Marcus and Hindle's proposal, prosodic information would not be limited to the presence of only obligatory major boundaries on this view. A full prosodic representation would also make available optional intonational phrase (IP) boundaries and intermediate phrase (ip) boundaries that happen to be present though they may not be grammatically required, as well as smaller boundaries and any other prosodic or intonational information. We doubt that boundaries are the only prosodic cues that influence early syntactic analysis of a sentence, and attempt to show this below.

\section{EXPERIMENT 1}

Experiment 1 tested the predictions of the Focus Attraction Hypothesis by assessing the preferred interpretations of auditorily presented sentences with complex NPs, like those in (17). Gilboy, Sopena, Clifton and Frazier (1995) reported that a number of factors affect the interpretation of similar visually presented sentences. They used a simple question-answering task in which readers were asked to choose which of two interpretations they had made of visually presented sentences containing relative clauses. In both Spanish and English, structural, referential and communicative factors were shown to affect the interpretation of ambiguous relative clauses, resulting in variation from $10 \%$ to $90 \%$ choice of $\mathrm{N}_{2}$ as head of the relative clause. 
The present experiment extends these observations to the auditory domain in an attempt to identify prosodic factors that also affect the interpretation of relative clauses. If the Focus Attraction Hypothesis (1) is correct, the relative clause should more frequently be interpreted as modifying $\mathrm{N}_{1}$ (technically, the NP headed by propeller) in $(17 \mathrm{a}, \mathrm{b})$ than in $(17 \mathrm{c}, \mathrm{d})$, whereas the opposite should hold true for the frequency with which the relative clause is interpreted as modifying $\mathrm{N}_{2}$ (plane):

17a. The sun sparkled on the PROPELLER of the plane that the mechanic was so carefully examining.

b. The sun sparkled on the PROPELLER near the plane that the mechanic was so carefully examining.

c. The sun sparkled on the propeller of the PLANE that the mechanic was so carefully examining.

d. The sun sparkled on the propeller near the PLANE that the mechanic was so carefully examining.

In Experiment 1, the Focus Attraction Hypothesis was investigated using moderately long relative clauses, which most naturally receive pitch accents when they are produced. We did this because of our concern with the possibility that the interpretation of a relative clause might be affected by the relation between its given versus new information status and the information structure of the phrases it might modify. A focused phrase (in particular, one of the possible NP hosts of the relative clause) will presumably be taken as new information. It is possible that an accented relative clause will similarly be taken as focused and new, and that a relative clause bearing new information will preferentially be taken to modify an informationally new NP. We test this possibility explicitly in Experiment 2, but in Experiment 1 we chose to sidestep it by using moderately long relative clauses, leaving the relative clauses ambiguous with respect to their informational status. A relatively long stretch of material, such as an Experiment 1 relative clause, is likely to form a separate intermediate phrase. Each intermediate phrase must contain a pitch accent. Thus, presence of a pitch accent in an Experiment 1 relative clause need not signal that the relative clause is focused or informationally new.

Experiment 1 also explored the generality of any effect by using two distinct sets of sentences. These two sets differed in that NP of NP designated a part-whole or inalienable possession relationship between $\mathrm{NP}_{1}$ and $\mathrm{NP}_{2}$ in the first set of sentences but not in the second set. Within each set, two forms of each sentence were constructed. In one form the preposition relating the two NPs was of, while in the other form the preposition varied (e.g. near, under, in, but not of). In the first set of sentences, the preposition of presumably introduces a phrase that is an argument of the first NP and 
transmits a thematic role from that NP, adding no lexical content of its own, whereas in the second set (and with a preposition other than of in general), the preposition contributes lexical content and introduces an adjunct of the first NP. These manipulations were designed to explore some suggestions made by Gilboy et al. (1995) about the differences between PPs that serve as arguments versus adjuncts of nouns. However, the manipulations did not appear to be successful (in that they did not result in the anticipated shifts in frequency of NP choice) and did not interact significantly with any of the other variables of interest. They will not be discussed further.

\section{Methods}

Materials. Two sets of eight sentences with ambiguously attached relative clauses were constructed. Two example sentences appear in Table 1. In all cases, the relative clause modified one of two noun phrases that constituted an NP in direct object position. These NPs appeared as a complex NP of the form $N P_{1} P R E P N P_{2}$. The two sets of eight sentences differed in that the NP of NP phrases in Set 1 designated a part-whole or inalienable possession relation between the two NPs, whereas in Set 2 they designated other relations. Each sentence had two versions, one with of as the preposition between the two NPs and one with some other, more substantive, preposition. All experimental sentences appear in Appendix 1.

An additional 36 sentences served as fillers. Eight of these had ambiguously attached relative clauses without any prominent accent on either potential head, and 16 had a sequence of prenominal adjectives. Twelve contained adjunct predicates (Clifton, Frazier, Rapoport, \& Radó, submitted) like "John hit Mary drunk", which were intended to provide another test of the Focus Attraction Hypothesis but which proved to have been pronounced in an excessively unnatural fashion.

All versions of all 50 sentences were recorded in a sound-attenuated chamber by a female linguistics student with phonetics training. She was instructed to place a prominent pitch accent on the capitalised (focused)

TABLE 1

Sample of the Relative Clause Sentences in Experiment 1

\section{Set 1: Part-whole or inalienable possession relationship in NP of NP}

$\mathrm{N}_{1}$ accented: The detective eyed the ENTRANCE of the house that showed clear signs of damage.

$\mathrm{N}_{2}$ accented: The detective eyed the entrance of the HOUSE that showed clear signs of damage.

\section{Set 2: Non-part-whole relationship in $N P$ of $N P$}

$\mathrm{N}_{1}$ accented: The tourists admired the MUSEUM of the city that they visited again in August. $\mathrm{N}_{2}$ accented: The tourists admired the museum of the CITY that they visited again in August. 
word of the sentence, and to avoid complete de-accenting of the relative clause. She was further instructed to avoid placing pauses or major boundary tones before the relative clause or between the two nouns. The resulting pronunciations were analysed both prosodically and acoustically.

A trained phonologist listened to all sentences and confirmed that the speaker had successfully followed the instructions for pronouncing the sentences. In addition, an analyst trained in the ToBI (Beckman \& Ayers, 1993 ) system for representing prosody transcribed the critical region of all of the sentences. The ToBI analyst was not associated with the present research and not informed of the purpose of the analyses. She checked the presence and kind $\left(\mathrm{H}^{*}, \mathrm{~L}+\mathrm{H}^{*}\right.$, etc.) of the pitch accents on $\mathrm{NP}_{1}$ and $\mathrm{NP}_{2}$, the strength of boundary between $\mathrm{NP}_{1}$ and the following $\mathrm{PP}$ (which contained $\mathrm{NP}_{2}$ ), and the strength of boundary between $\mathrm{NP}_{2}$ and the relative clause. A second ToBI analyst performed acoustic analyses of selected sentences on a Sun Workstation using the Waves program to confirm the transcriptions made by the first.

Table 2 includes summary information about the frequencies of pitch accents at critical points in the sentences. Clearly, $\mathrm{H}^{*}$ pitch accents occurred where the speaker had intended them, with few accents elsewhere in the critical regions of the sentences.

The boundary between $\mathrm{NP}_{1}$ and $\mathrm{NP}_{2}$ was of break index 1 (phrase-medial word boundary) in all cases, as intended. Table 3 also summarises the frequencies of boundaries of various strengths before the relative clause. ${ }^{2}$ This boundary had a clear level 3 break index (corresponding to an

TABLE 2

Frequencies of Pitch Accents in Experiment 1

\begin{tabular}{lcccccc}
\hline & $\begin{array}{c}\text { Pitch Accent on } N P_{1} \\
\text { Position }\end{array}$ & & \multicolumn{2}{c}{$\begin{array}{c}\text { Pitch Accent on } N P_{2} \\
\text { Position }\end{array}$} \\
\cline { 2 - 3 } \cline { 5 - 6 } Value & $N P_{1}$ & $N P_{2}$ & & $N P_{1}$ & $N P_{2}$ \\
\hline None & 0 & 18 & & 27 & 0 \\
None/downstepped & 0 & 8 & & 0 & 0 \\
$\mathrm{H}^{*}$ & 32 & 1 & & 5 & 32 \\
$\mathrm{H}^{*} /$ downstepped & 0 & 5 & & 0 & 0 \\
\hline
\end{tabular}

\footnotetext{
${ }^{2}$ In the ToBI system, break level 0 marks the break between words in a clitic group; level 1 marks typical word breaks within an intermediate phrase; level 2 marks a "sense of disjuncture" corresponding to either pause or lengthening information consistent with an intermediate phrase or pitch movement consistent with an intermediate phrase, but not both; level 3 marks a break consistent with evidence (from both timing and intonation) of an intermediate phrase; level 4 corresponds to an intonational phrase boundary; and levels 5 and 6 correspond to IP boundaries with longer pauses or more lengthening than at index 4 .
} 
TABLE 3

Frequencies of Break Indices in Experiment 1

\begin{tabular}{lccccc}
\hline & \multicolumn{2}{c}{$\begin{array}{c}\text { Pitch Accent on } N P_{I} \\
\text { Position }\end{array}$} & & \multicolumn{2}{c}{$\begin{array}{c}\text { Pitch Accent on } N P_{2} \\
\text { Position }\end{array}$} \\
\cline { 2 - 3 } \cline { 5 - 6 } Break Index & Before $N P_{2}$ & Before $R C$ & & Before $N P_{2}$ & Before $R C$ \\
\hline $0-1$ & 32 & 1 & & 32 & 0 \\
2 & 0 & 2 & & 0 & 1 \\
$2-3$ & 0 & 5 & & 0 & 6 \\
3 & 0 & 25 & & 0 & 25 \\
$4+$ & 0 & 0 & & 0 & 0 \\
\hline
\end{tabular}

intermediate phrase break in the ToBI system) in 50 of the possible 64 instances. In another 11 instances, the boundary had a break index that was judged to be either a 2 (partial evidence for an intermediate phrase break) or a 3; 5 of these 11 instances occurred when $\mathrm{NP}_{1}$ received the pitch accent and 6 when $\mathrm{NP}_{2}$ did. A final three sentences had a clear level 2 break index, two when $\mathrm{NP}_{1}$ received pitch accent and one when $\mathrm{NP}_{2}$ did. In sum, all of the breaks before the relative clause were stronger than a phrase-medial word boundary but weaker than an intonational phrase (IP) boundary, within the range that corresponds to an intermediate phrase boundary.

A simple acoustic analysis of the experimental sentences was conducted using a Macintosh computer and the Signalyze program. This analysis confirmed the identification of $\mathrm{H}^{*}$ pitch accents made in the ToBI analysis. It recorded several extreme points in the fundamental frequency (F0) plots for each sentence, including the highest points of $\mathrm{NP}_{1}$ and of $\mathrm{NP}_{2}$ and the lowest point near the beginning of the relative clause. These extreme points were chosen to reflect phonologically critical points in the pitch track rather than reflecting phonetic interpolation at intermediate points. The F0 values at these points appear in Table 4. The pitch measurements indicated that the manipulations of accent were successful, in that the peak pitch on $\mathrm{NP}_{1}$ was higher when $\mathrm{NP}_{1}$ received accent than when $\mathrm{NP}_{2}$ did $\{257$ vs $223 \mathrm{~Hz}$; $F(1,14)=54.23, P<0.001\}$. The converse held when pitch of $\mathrm{NP}_{2}$ was examined $\{219$ vs $247 \mathrm{~Hz} ; F(1,14)=62.09, P<0.001\}$.

Each sentence was digitised using an IBM-compatible personal computer. Both "normal" and "cross-spliced" versions of each sentence were prepared, to ensure that no irrelevant differences in the pronunciation of the relative clause that might have been associated with the difference between accent on $\mathrm{NP}_{1}$ versus $\mathrm{NP}_{2}$ could be responsible for any observed difference between these two conditions. Each of the experimental relative clause sentences was divided (at a zero-crossing at the beginning of the relative clause) into two regions, and each region (pre-RC and RC) was stored as a separate computer file. The resulting computer files were digitally re- 
TABLE 4

Average Pitch (F0) Values at Critical Points in the Sentences in Experiment 1

\begin{tabular}{lccc}
\hline Sentence Form & $N P_{1}$ Peak & $N_{2}$ Peak & RC Initial Low \\
\hline Set 1 & & & \\
Prep of, $\mathrm{NP}_{1}$ accented & 268 & 228 & 195 \\
Prep not of, $\mathrm{NP}_{1}$ accented & 258 & 218 & 193 \\
Prep of, $\mathrm{NP}_{2}$ accented & 222 & 244 & 210 \\
Prep not of, $\mathrm{NP}_{2}$ accented & 231 & 248 & 196 \\
& & & \\
Set 2 & & & 196 \\
Prep of, $\mathrm{NP}_{1}$ accented & 253 & 215 & 193 \\
Prep not of, $\mathrm{NP}_{1}$ accented & 251 & 212 & 194 \\
Prep of, $\mathrm{NP}_{2}$ accented & 221 & 246 & 194 \\
Prep not of, $\mathrm{NP}_{2}$ accented & 219 & 251 & \\
\hline
\end{tabular}

Note: $\mathrm{NP}_{1}$ Peak $=$ highest $\mathrm{F} 0$ point in $\mathrm{NP}_{1} ; \mathrm{NP}_{2}$ Peak $=$ highest $\mathrm{F} 0$ point in $\mathrm{NP}_{2}$; $\mathrm{RC}$ Initial Low $=$ lowest $\mathrm{F} 0$ point in early region of relative clause.

combined in their original pairs to form "normal" sentences and were cross-spliced (so that the $\mathrm{RC}$ which was recorded with $\mathrm{NP}_{1}$ accent was spliced to the sentence in which $\mathrm{NP}_{2}$ was accented, and vice versa) to form the "cross-spliced" sentences. All sentences were recorded onto audiotape. Eight different audiotapes were used, using a Latin square counterbalancing scheme to assign particular sentence forms to tapes. There were eight forms of each experimental sentence: $\mathrm{NP}_{1}$ or $\mathrm{NP}_{2}$ was accented, the preposition was of or some other preposition, and the sentence was "original" or "cross-spliced". Each sentence occurred in each form on one tape, and each tape contained one sentence from each set in each form. A different random order of sentences was used for each tape. A single tape containing six practice sentences was also made.

Subjects and Procedures. Forty-eight University of Massachusetts students served as subjects, receiving course credit for their participation. Each was tested individually in a quiet room, and six subjects were assigned to each tape in a rotating fashion. The sessions lasted approximately $20 \mathrm{~min}$. Each subject first heard the practice tape and then the assigned experimental tape. The experimenter stopped the tape after each sentence to permit the subject to answer a simple question presented by the experimenter. The question was about the head of the relative clause in the experimental sentences, and about some other aspect of the filler sentences. For instance, following the sentences shown in Table 1, the question was "What showed signs of damage?" or "What did the tourists visit in August?" The experimenter recorded the subject's answer by circling one of four alternative answers (none of which was visible to the experimental participant), including $\mathrm{NP}_{1}$ (e.g. the entrance), $\mathrm{NP}_{1} \mathrm{PREPNP}_{2}$ (e.g. the 
entrance of the house), $\mathrm{NP}_{2}$ (the house), and "other" (in which case the experimenter wrote down the alternative, which included memory failures, failures to respond, mishearings of the auditory sentence, and other errors). The first two answers were taken to indicate a high attachment of the relative clause $\left(\mathrm{NP}_{1}\right.$ or NP PREP NP) and the third a low attachment $\left(\mathrm{NP}_{2}\right)$.

\section{Results}

The data can be scored in terms of "low attachments" (frequency of $\mathrm{NP}_{2}$ choices) or in terms of "high attachments" (frequency of $\mathrm{NP}_{1}$ and $\mathrm{NP}_{1}$ PREP NP $\mathrm{N}_{2}$ choices). These are essentially the complements of one another, except for the infrequent occurrence of "other" responses. To permit comparison with Experiment 2, which manipulates only $\mathrm{NP}_{2}$ accent, we present our analyses in terms of $\mathrm{NP}_{2}$ percentages. The full distribution of actual numbers of choices made appears in Appendix 2.

The percentages of $\mathrm{NP}_{2}$ (low attachment) interpretations of the relative clause sentences are shown in Table 5, and were subjected to a four-factor analysis of variance. Placement of accent significantly affected interpretation. Choices of $\mathrm{NP}_{2}$ were more frequent when it was accented than when $\mathrm{NP}_{1}$ was accented: 41 vs $31 \% \quad\left\{F_{1}(1,47)=8.13, \quad P<0.01\right.$; $\left.F_{2}(1,14)=13.59, P<0.01\right\}^{3}$

While no effect involving cross-splicing (original vs cross-spliced items) was significant in the analysis by subjects, it was involved in several

TABLE 5

Percentages of $\mathrm{NP}_{2}$ Choice in Experiment 1, Relative Clauses

\begin{tabular}{|c|c|c|c|}
\hline Accented Item & Preposition $=$ of & Preposition of & Mean \\
\hline $\mathrm{N}_{1}$ & 34.9 & 27.1 & 31.0 \\
\hline $\mathrm{N}_{2}$ & 47.4 & 34.9 & 41.1 \\
\hline
\end{tabular}

${ }^{3}$ The only other effect that was conventionally significant reflected the higher percentage of $\mathrm{NP}_{2}$ choices for sentences with of as the preposition between the two NPs than for sentences with a lexical preposition: 41 vs $31 \%\left\{F_{1}(1,47)=6.43, P<0.02 ; F_{2}(1,14)=4.65, P<0.05\right\}$. This difference was equally present for both sets of items, Set 1 and Set 2, although not fully significant in either taken by itself. This difference is opposite in direction to what we had taken to be the corresponding effect reported in Gilboy et al. (1995), who reported a lower percentage of $\mathrm{NP}_{2}$ choices for sentences with the preposition of between the two NPs than for sentences with the preposition with. The difference was also observed in a visual sentence interpretation study. Twenty-four members of the University of Massachusetts community indicated their interpretation of visually presented versions of the sentences used in Experiment 1: $54 \%$ chose the $\mathrm{NP}_{2}$ reading for the presumed-argument sentences, with the preposition of, while $39 \%$ chose that reading for the presumed-adjunct sentences, with other prepositions. We can offer no convincing account of this apparent discrepancy or for why overall frequency of $\mathrm{NP}_{2}$ choices was lower for auditory than for visual sentences. 
interactions in the items analysis, including the four-way interaction $\left\{F_{2}(1,14)=5.72, P<0.05\right.$; but $\left.F_{1}(1,47)=1.77, P>0.18\right\}$. Since there was a numerical effect of accent placement in each comparison that contributed to this interaction except for the Set 1, cross-spliced, non-"of" items (where $\mathrm{NP}_{2}$ was chosen $31 \%$ of the time when $\mathrm{NP}_{1}$ was accented, but only $29 \%$ of the time when $\mathrm{NP}_{2}$ was accented), and since the interactions were not significant by subjects, we do not think that they seriously qualify the conclusion that accenting an NP increases its tendency to attract relative clauses (see Appendix 2 for more details).

\section{Discussion}

The secure conclusion from Experiment 1 is that pitch accent is one factor that affects the perceiver's analysis of ambiguous relative clauses. The break index analysis (Table 3) indicates that the greater number of choices of $\mathrm{NP}_{2}$ as head of the relative clause when it received pitch accent than when $\mathrm{NP}_{1}$ did cannot be attributed to differences in prosodic boundaries. Thus, Experiment 1 confirms the predictions of the Focus Attraction Hypothesis as it applies to relative clause interpretation.

However, another explanation should be considered. It is possible that the observed effect could be attributed to variations in given/new information status, variations that are signalled by focus or pitch accent. Experiment 2 was designed to distinguish between the original Focus Attraction Hypothesis and the Congruence Hypothesis, which appeals to information structure. It also explored a potential effect which was dismissed as playing a role in the Experiment 1 findings, but may nonetheless be important; namely, the possibility that the nature or extent of the intonational boundary between $\mathrm{NP}_{2}$ and the relative clause affects interpretation of the relative clause.

\section{EXPERIMENT 2}

The results of Experiment 1 supported the Focus Attraction Hypothesis for relative clauses and suggested that focus, as marked by a pitch accent, does play a role in syntactic disambiguation. However, Experiment 1 included only long relative clauses which were ambiguous with respect to their given/new status. Experiment 2 explicitly tested the effects of the relative clause's given/new status. Short relative clauses were used which were either prosodically accented, appropriate for a relative clause conveying new information, or prosodically unaccented, appropriate for a relative clause conveying given information. This manipulation when combined with a manipulation of the accent placed on the potential NP head of the relative clause (described below) allowed us to compare the Focus Attraction Hypothesis (1), under which focused phrases generally attract modifier 
phrases, to the Congruence Hypothesis (2), which claims that the information structure of the modifier phrase influences its attraction to the focused phrase.

Previous research indicates that new and given information are produced and perceived differently. In production, new information receives more accent in one or more of the parameters of duration, amplitude and pitch excursion than old information (Fowler \& Housum, 1987; see also Bolinger, 1986; Lieberman, 1967). This effect holds for words defined as "old" or "new" in terms of the information structure of both natural and read discourses, but crucially does not hold when two homophones (phonologically identical but lexically different) appear in a discourse, or when words in a list are repeated (Fowler, 1988).

Work on word perception has shown that new versus old tokens can be distinguished from each other and that new words are more easily identified than old words when excised from their context (Fowler \& Housum, 1987). Work on sentence comprehension has shown that a word marked as old facilitates the retrieval of an earlier context better than a word marked as new and that congruent accentuation, with new information receiving accent and given information being unaccented, facilitates both verification of pictures (Terken \& Nooteboom, 1987) and simple comprehension times of sentences (Bock \& Mazella, 1983). These findings suggest that the accentual status of a phrase directs how the processor treats it (Clark \& Haviland, 1977). While given information is matched to an antecedent already in the discourse representation, new information requires fuller phonological parsing (Cutler, 1976) and the creation of a new discourse entity.

Experiment 2 examines the given/new distinction in processing modifiers. It also explores further the relevance of information structure to sentence processing operations. In addition to the manipulation of the prominence of the relative clause, the prominence of the focused phrase was varied. $\mathrm{NP}_{2}$ was pronounced with a pitch accent intended to be appropriate for a new phrase $\left(\mathrm{H}^{*}\right)$ or with a contrastive pitch accent $\left(\mathrm{L}+\mathrm{H}^{*}\right)$ (Bartels \& Kingston, 1994; Pierrehumbert \& Hirschberg, 1990). A contrastive accent, like a new accent, focuses the NP, but unlike a new accent is consistent with the NP having been mentioned previously in the discourse. The pitch accent variation was limited to only one $\mathrm{NP}, \mathrm{NP}_{2}$, to make the design manageable.

Including both given and new relative clauses allows the comparison of the Focus Attraction Hypothesis and the Congruence Hypothesis (repeated below):

1. Focus Attraction Hypothesis: A phrase that is neither a complement nor syntactically obligatory is preferentially taken to modify a focused phrase unless this violates linguistic (grammatical or pragmatic) constraints. 
2. Congruence Hypothesis: A modifier marked as conveying new information preferentially is related to another phrase also marked as new (and a modifier marked as conveying given information preferentially is related to another phrase also marked as given).

The Focus Attraction Hypothesis simply claims that a relative clause, prosodically accented or unaccented, will be favoured as modifying a focused phrase. Any effect of accent on the relative clause should be additive with the effect of accent on the NP. The Congruence Hypothesis, on the other hand, claims that any apparent preference for a relative clause to modify a focused phrase actually reflects a preference for informational congruence. A relative clause will be taken to convey given information if it is unaccented. A relative clause that conveys given information should in general not be taken to modify an NP whose informational status is marked by focal accent as "new". However, it could be taken to modify an NP marked by contrastive accent, since such an NP can represent given information. A prosodically accented relative clause, on the other hand, is taken as new information, and can modify either an informationally new or an informationally old NP. Therefore, the frequency of choice of $\mathrm{NP}_{2}$ as head should exhibit an interaction between type of accent on $\mathrm{NP}_{2}$ and presence of accent on the relative clause; relatively few choices would be expected in the non-contrastive accent on $\mathrm{NP}_{2}$, unaccented relative clause condition.

\section{Methods}

Materials. One set of 16 experimental sentences was constructed. Each contained a short sentence-final relative clause preceded by a complex NP in object position. Preliminary norms were gathered from 24 University of Massachusetts students who read 18 sentences of the form NPVerb $N P_{1}$ of $\mathrm{NP}_{2} R C$, answering a question about the relative clause immediately after each sentence. Two sentences were discarded to yield 16 sentences that had the most nearly balanced choices of $\mathrm{NP}_{1}$ and $\mathrm{NP}_{2}$. However, even these yielded an average of $71 \% \mathrm{NP}_{2}$ choices.

Four forms of each sentence were constructed, varying in whether $\mathrm{NP}_{2}$ received focal or contrastive accent, and whether the relative clause was prosodically accented or unaccented. A context sentence was made up for each form of each sentence, to aid the speaker in rendering appropriate pronunciations of the sentence. In the new/focal accent condition, the context sentence simply provided a discourse context into which the focused NP could be plausibly introduced. In the contrastive accent condition, on the other hand, the context sentence provided a referent with which the contrastive NP could be explicitly contrasted. The context sentences were 
not presented to the subjects in the experiment. One sample sentence, in all four forms and with context sentences, appears in Table 6; all 16 sentences appear in Appendix 3.

Thirty-six filler sentences were constructed, including nine additional ambiguous relative clause sentences with stress on $\mathrm{NP}_{1}$, nine unambiguous relative clause sentences without focal or contrastive accent on either possible NP head, nine sentences without relative clauses that contained some other syntactic ambiguity, and nine other unambiguous sentences. Six practice sentences were also constructed.

All sentences were recorded by the same speaker who recorded the Experiment 1 sentences, who was instructed to avoid placing an accent on $\mathrm{NP}_{1}$, to place the intended accent on $\mathrm{NP}_{2}$, and to avoid breaks between $\mathrm{NP}_{1}$ and $\mathrm{NP}_{2}$ and between $\mathrm{NP}_{2}$ and the relative clause. The sentences were then digitised using an IBM-compatible personal computer. Each was saved as a waveform file for playback during the experiment. In addition, the end of each sentence, from the determiner of $\mathrm{NP}_{2}$ through the end of the relative clause, was captured and saved as a file for acoustic analysis.

Subjective, Acoustic and Phonological Analyses. The adequacy and nature of the prosodic manipulations were evaluated in several ways. First, six subjects naive to the purpose of the experiment, all members of the University of Massachusetts community, listened to all four versions of each of the 16 experimental sentences and matched the intonational contour of

TABLE 6

Sample Item in Experiment 2, with Context Sentence (Not Presented to Subject)

New $\mathrm{NP}_{2}$, prosodically accented relative clause

(Some guy at the Advocate is doing a series where he interviews the sisters of famous people.) The reporter recently interviewed the sister of the SENATOR who was so CONTROVERSIAL.

Contrastive $\mathrm{NP}_{2}$, prosodically accented relative clause

(The reporter didn't recently interview Al Gore's sister.) The reporter recently interviewed the sister of the senator who was so CONTROVERSIAL.

\section{New $\mathrm{NP}_{2}$, prosodically unaccented relative clause}

(Some guy at the Advocate is doing a series where he interviews the sisters of famous people who are controversial.) The reporter recently interviewed the sister of the SENATOR who was so controversial.

\section{Contrastive $\mathrm{NP}_{2}$, prosodically unaccented relative clause}

(The reporter didn't recently interview the sister of the nun who was so controversial.) The reporter recently interviewed the sister of the senator who was so controversial.

Note: Words in CAPITALS received focal accent; words that are underlined received contrastive accent. 
each against two "prosodic cartoons", one of which showed a single pitch peak near the start of the sentence with a gradual decline through the rest of the sentence, and the other of which showed the same initial pitch peak but a second peak near the end of the sentence (approximately $80 \%$ of the way through the cartoon, corresponding to the relative clause). The subjects chose the single-peak cartoon as matching the prosodically unaccented relative clause sentences $79 \%$ of the time $(74 \%$ for the focal accent sentences, $84 \%$ for the contrastive stress sentences). On the other hand, they chose the single-peak cartoon as matching the prosodically accented relative clause sentences only $28 \%$ of the time ( $30 \%$ focal accent, $26 \%$ contrastive stress). The difference between the percentage choices in the prosodically accented and the prosodically unaccented conditions was highly significant in an analysis permitting generalisation to items $\left\{F_{2}(1,15)=143.68, P<0.01\right\}$, but the effect of type of accent on $\mathrm{NP}_{2}$ and its interaction with relative clause accent were not significant $(F<1)$. The accented relative clause sentences thus seem to contain a more noticeable subjective pitch peak in the relative clause than do the unaccented relative clause sentences.

Acoustical analyses were done on the $\mathrm{NP}_{2} \mathrm{RC}$ region of each sentence, to measure the acoustic properties of the accented words and to search for any other phonological effects associated with accent placement (including, as it turns out later, the occurrence of intermediate and, perhaps, intonational phrase boundaries between $\mathrm{NP}_{2}$ and the $\mathrm{RC}$ in some conditions). Fundamental frequency analyses were performed for each sentence using the Signalyze program on a Macintosh computer. Average pitch extreme patterns were computed for each type of sentence as in Experiment 1. The following inflection points or pitch extremes were identified in the pitch track for each sentence: (a) lowest pitch at or near the start of $\mathrm{NP}_{2}$; (b) highest point anywhere in $\mathrm{NP}_{2}$; (c) lowest point at or near (but before) the end of $\mathrm{NP}_{2}$; (d) initial high point in $\mathrm{RC}$, always present and followed by a fall; (e) lowest point at or near the start of the RC; (f) highest point anywhere in the RC; and ( $\mathrm{g}$ ) lowest point at or near the end of the RC. These points were chosen because they should directly reflect phonologically relevant aspects of the prosodic representation; being extremes they could not reflect phonetic interpolation. The fundamental frequency value of each of these points was recorded for each sentence, together with how much time (msec) had elapsed between the beginning of the determiner in $\mathrm{NP}_{2}$ and the measurement point. The means of both these values were computed for each of the four sentence forms. They are presented graphically in connected fashion as average pitch extremes in Fig. 1.

Inspection of Fig. 1 makes it clear that maximum pitch in $\mathrm{NP}_{2}$ was higher for contrastively stressed than focally accented items $\{293$ vs $250 \mathrm{~Hz}$; $F(1,15)=47.27, P<0.001\}$, and the duration of $\mathrm{NP}_{2}$ was longer when it was contrastively accented than when it received a new accent $\{649$ vs $574 \mathrm{msec}$; 
(a)

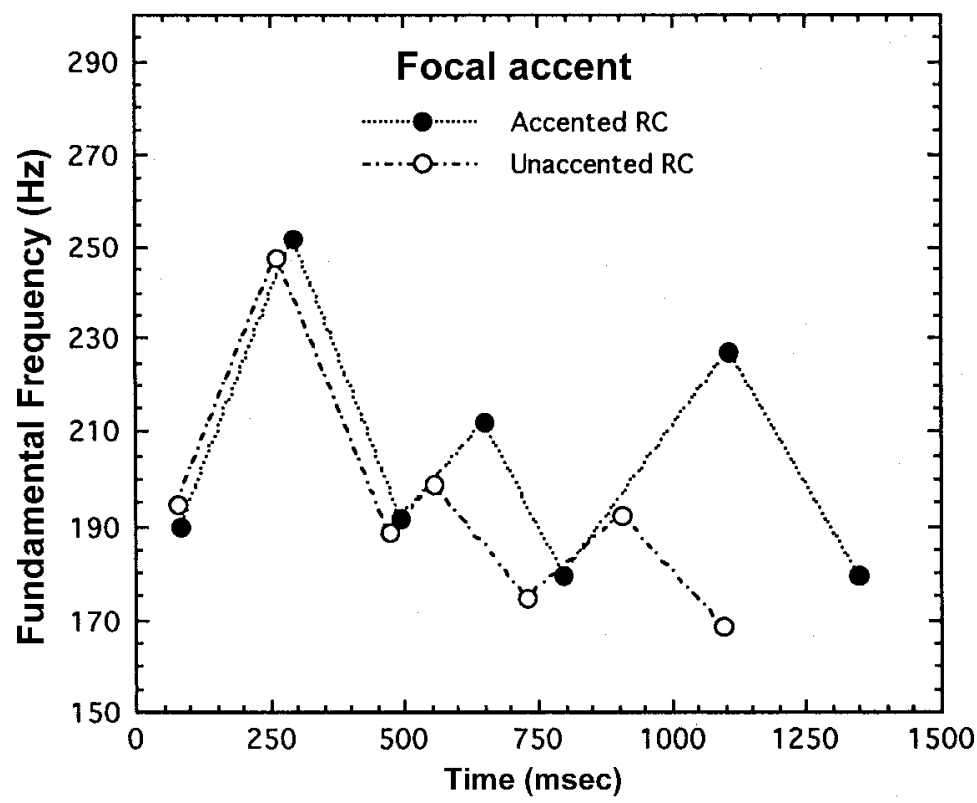

(b)

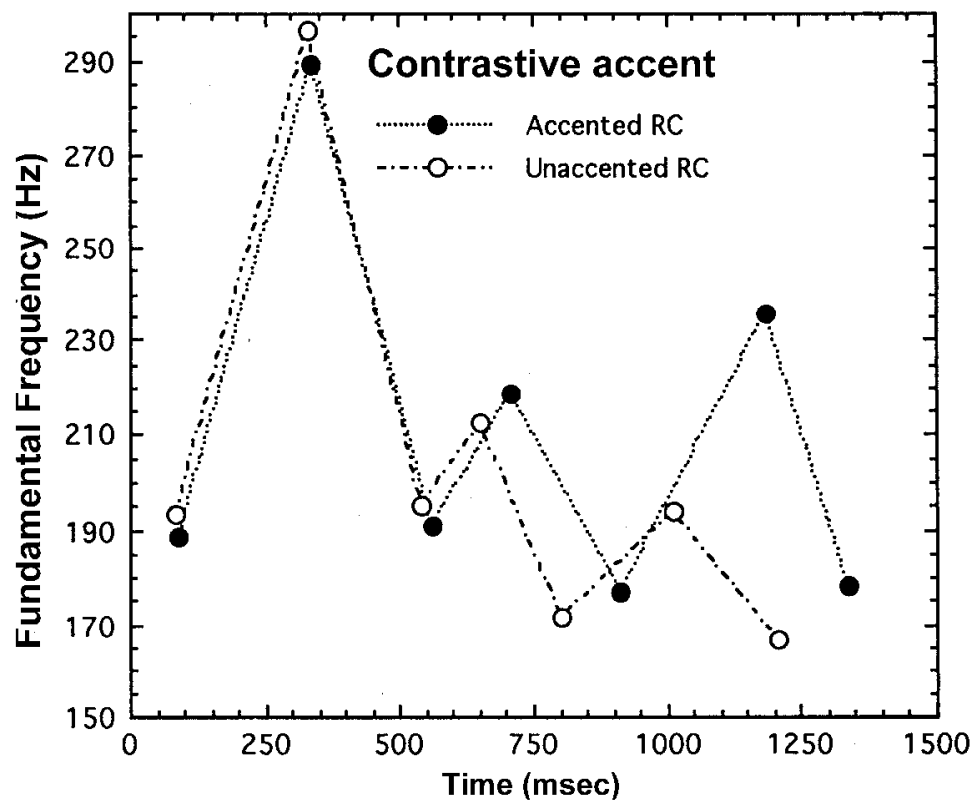

FIG. 1. Average pitch extremes for sentences containing relative clauses with and without pitch accents. (a) Focal accent on $\mathrm{N}_{2}$; (b) contrastive accent on $\mathrm{N}_{2}$. The points on the graphs correspond to (1) lowest point near start of $\mathrm{NP}_{2}$; highest point in $\mathrm{NP}_{2}$; lowest point near end of $\mathrm{NP}_{2}$; initial high point in RC; lowest point near start of RC; highest point in RC; and lowest point near end of RC. 
$F(1,15)=39.91, P<0.001\}$. The maximum pitch in the RC was higher when the RC was prosodically accented than when it was unaccented $\{231 \mathrm{vs}$ $193 \mathrm{~Hz} ; F(1,15)=85.70, P<0.001\}$ and the duration of the RC (measured from the final low point of $\mathrm{NP}_{2}$ ) was greater $\{931 \mathrm{vs} 863 \mathrm{msec} ; F(1,15)=9.33$, $P<0.01\}$. These results confirm and extend the subjective judgements presented earlier.

In addition, the acoustic analysis indicated the presence of a clearer phonological boundary between $\mathrm{NP}_{2}$ and the RC when the RC was prosodically accented than when it was unaccented. The average pitch rise between the low at the end of $\mathrm{NP}_{2}$ and the initial high in the $\mathrm{RC}$ was greater for accented RCs than for the unaccented ones $\{24 v s 14 \mathrm{~Hz} ; F(1,15)=6.72$, $P<0.03\}$ and the temporal extent of this rise was also longer when the RC was accented $\{151.7$ vs $98.3 \mathrm{msec} ; F(1,15=12.57, P<0.003\}$, suggesting some lengthening at the boundary before the accented relative clause.

Prosodic analyses were also conducted using the ToBI system, as in Experiment 1 . The analyses assessed the pitch accents on $\mathrm{NP}_{1}$ and $\mathrm{NP}_{2}$, the strength of boundary between $\mathrm{NP}_{1}$ and $\mathrm{NP}_{2}$, and the strength of boundary between $\mathrm{NP}_{2}$ and the relative clause. The transcriptions confirmed that there were no pitch accents on $\mathrm{NP}_{1}$ and no break index stronger than 1 between the two NPs. The pitch accents on $\mathrm{NP}_{2}$ are summarised in Table 7 . NPs with new/focal accent tended to have simple $\mathrm{H}^{*}$ pitch accents, while NPs with contrastive accent tended to have $\mathrm{L}+\mathrm{H}^{*}$ pitch accents. Sentences with accented and unaccented RCs did differ somewhat in terms of the prosodic boundary before the RC, as shown in Table 8 . Stronger boundaries were more likely to occur before an accented RC than before an unaccented RC. However, the kind of accent (focal $v s$ contrastive) on $\mathrm{NP}_{2}$ did not have any substantial influence on the nature of the boundary before the RC.

Subjects and Procedures. Fifty-six University of Massachusetts students were tested individually in 20-min sessions in a sound-attenuated chamber. An IBM-compatible computer played the six practice sentences followed by the 52 sentences in the main experiment using an Audio Media PAS-16

TABLE 7

Frequencies of Pitch Accents at $\mathrm{NP}_{2}$ in Experiment 2

\begin{tabular}{lcccc}
\hline $\begin{array}{l}\text { Pitch } \\
\text { Accent }\end{array}$ & $\mathrm{NP}_{2}$ New, & $\mathrm{NP}_{2}$ Contrastive, & $\mathrm{NP}_{2}$ New, & $\mathrm{NP}_{2}$ Contrastive, \\
Value & $R C$ Accented & $R C$ Accented & $R C$ Unaccented & RC Unaccented \\
\hline None & 0 & 0 & 0 & 0 \\
$\mathrm{H}^{*}$ & 14 & 5 & 16 & 5 \\
$\mathrm{~L}+\mathrm{H}^{*}$ & 0 & 10 & 0 & 11 \\
$\mathrm{H}^{*}+\mathrm{L}$ & 2 & 1 & 0 & 0 \\
\hline
\end{tabular}


TABLE 8

Frequencies of Break Index Values Before RC in Experiment 2

\begin{tabular}{|c|c|c|c|c|}
\hline $\begin{array}{l}\text { Break } \\
\text { Index } \\
\text { Value }\end{array}$ & $\begin{array}{c}\mathrm{NP}_{2} \mathrm{New}, \\
\text { RC Accented }\end{array}$ & $\begin{array}{l}\mathrm{NP}_{2} \text { Contrastive } \\
\quad \mathrm{RC} \text { Accented }\end{array}$ & $\begin{array}{c}\mathrm{NP}_{2} \mathrm{New}, \\
\text { RC Unaccented }\end{array}$ & $\begin{array}{l}\mathrm{NP}_{2} \text { Contrastive, } \\
\mathrm{RC} \text { Unaccented }\end{array}$ \\
\hline $0-1$ & 0 & 1 & 1 & 0 \\
\hline 2 & 3 & 0 & 3 & 2 \\
\hline $2-3$ & 0 & 1 & 5 & 4 \\
\hline 3 & 12 & 13 & 7 & 10 \\
\hline 4 & 1 & 1 & 0 & 0 \\
\hline
\end{tabular}

digital sound board and Radio Shack Minimus-16 speakers. Each subject heard an individually randomised order of the sentences, receiving four of the 16 experimental sentences in each condition (focal $v s$ contrastive stress $\times$ presence $v s$ absence of pitch accent on the relative clause). Latin-square counterbalancing procedures were followed so that each sentence was tested in each condition for equal numbers of subjects. After playing a sentence, the computer displayed a question (about the relative clause in the case of the experimental sentences, e.g. "Who was so controversial?") together with two alternative answers corresponding to $\mathrm{NP}_{1}$ and $\mathrm{NP}_{2}$ ("the sister ... the senator"), and the subject was instructed to pull a lever under the answer that corresponded to his or her understanding of the sentence.

\section{Results}

The mean percentages of choice of $\mathrm{NP}_{2}$ appear in Table 9. Each main effect was highly significant. The second NP was chosen as host of the relative clause more frequently when it was contrastively stressed than when it received focal accent: $66 v s 52 \%\left\{F_{1}(1,55)=12.04, P<0.01 ; F_{2}(1,15)=13.34\right.$, $P<0.01\}$. Furthermore, the second NP was chosen more frequently when the relative clause was prosodically unaccented than when it was accented: 65 vs $53 \%\left\{F_{1}(1,55)=14.77, P<0.01 ; F_{2}(1,15)=15.55, P<0.01\right\}$. As is clear from inspection of Table 9, there was no interaction between these two factors $(F \ll 1)$.

TABLE 9

Percentages of $\mathrm{NP}_{2}$ Choices in Experiment 2

\begin{tabular}{lccc}
\hline & \multicolumn{2}{c}{ Relative Clause Prosody } & \\
\cline { 2 - 3 } Type of Accent & Accented & Unaccented & Mean \\
\hline Focal accent on $\mathrm{N}_{2}$ & 45.5 & 58.9 & 52.2 \\
Contrastive accent on $\mathrm{N}_{2}$ & 60.3 & 71.0 & 66.0 \\
Mean & 52.9 & 65.0 & \\
\hline
\end{tabular}




\section{Discussion}

We advanced two hypotheses (1 and 2): Focus Attraction and Congruence. The Congruence Hypothesis (2) predicted that a prosodically unaccented relative clause, representing given information, should not be taken to modify an NP that is marked by accent as representing new information, but could be taken to modify a potentially given NP that is marked by contrastive accent. The data that were obtained provided no support for this hypothesis. Instead, support was found for (1), Focus Attraction. Contrastively accented NPs attracted relative clauses more frequently than focally accented NPs, an effect which held for both prosodically accented and unaccented relative clauses. The observed difference between contrastive and focal accent may be due to the acoustic salience of contrastive accents, which is consistent with the common belief that speakers use contrastive accent precisely in order to direct the attention of listeners to the contrastively accented phrase.

In addition, placing accent on a relative clause reduced the likelihood it would be taken as modifying $\mathrm{NP}_{2}$. We have suggested that the accent resulted in the appearance of a stronger phonological boundary between the complex $N P_{1}$ of $N P_{2}$ and the relative clause. We further suggested that such a boundary encourages a high attachment interpretation of the following phrase. High attachment in the present case is equivalent to the RC modifying the entire complex NP. Since the head of this complex NP is $\mathrm{NP}_{1}$, such an attachment will appear as increased choice of $\mathrm{NP}_{1}$ as host for the relative clause.

\section{CONCLUSIONS}

We have presented evidence for the following points:

18. Focus attracts modifiers (relative clauses).

19. Pitch accents for new phrases differ acoustically from pitch accents for contrastive phrases; the latter are associated with higher peak values and longer durations and, frequently, with $\mathrm{L}+\mathrm{H}^{*}$ rather than $\mathrm{H}^{*}$ pitch accents; they may represent phonologically distinct prosodic categories (cf. Bartels \& Kingston, 1994).

20. Prosodically unaccented ("given") relative clauses show no distinctive preference for a head that could represent given information (a contrastively accented NP, as opposed to an NP with focal accent), contrary to the Congruence Hypothesis that the given/new information status of the head and of the relative clause should be the same.

21. The presence of a pitch accent on the relative clause was associated with the presence of a stronger prosodic boundary before the relative clause. 
22. The presence of a prosodic boundary before the relative clause biases listeners towards high $\left(\mathrm{NP}_{1}\right)$ responses.

We will discuss these points in turn.

The presence of a pitch accent on a phrase conveys focus, which can signal that the phrase is new and/or important, directing the listener's attention to the phrase (e.g. Cutler, 1976). The basic finding (18), that the presence of pitch accent attracts a relative clause (Experiments 1 and 2), suggests that listeners preferentially relate adjuncts to important information in the sentence.

Turning to (19), acoustic and phonological contrasts between "new" and "contrastively" accented phrases have been demonstrated previously and have been interpreted in terms of a distinction between two types of formal entities in phonological theory (e.g. $\mathrm{H}^{*} v s \mathrm{~L}+\mathrm{H}^{*}$; cf. Bartels \& Kingston, 1994; Pierrehumbert \& Hirschberg, 1990). However, we are not aware of previous experimental demonstrations of a systematic difference in comprehension between the two types of accents. At the present time, we cannot decide with certainty whether the differences we observed can be attributed directly to the acoustic differences between the two types of accent (higher peaks and longer durations for contrastively accented phrases than for focally accented phrases), or to the existence of a difference in phonological category.

Point (20) is of particular interest in that it indicates that attraction to a focally accented head is not restricted to relative clauses pronounced in such a way that they could express new information (Experiment 1 and the accented relative clauses of Experiment 2). A focal pitch accent (as well as a contrastive one) attracts even a prosodically unaccented relative clause (Experiment 2). The generality of the focus attraction effect suggests that it is really focus, in its role of marking significant information, that is at work, and not some tendency to avoid an interpretation where given or old information is taken as a modifier or restrictor on a new (accented) phrase.

We have argued on the basis of perceptual judgements and acoustic and phonological analyses that a stronger prosodic boundary tends to precede the accented clauses than the unaccented relative clauses of Experiment 2 (point 21). The tendency for a pitch accent on the relative clause to induce a prosodic boundary before the relative clause is consistent with existing theories of intonation. However, intonational theory does not force the occurrence of a boundary before a relative clause containing a pitch accent, as far as we know. Presumably, a theory of how speakers choose between available grammatical options in intonating a sentence should explain the tendency and naturalness of placing a boundary before the accented relative clause. 
We attributed the smaller number of $\mathrm{NP}_{2}$ responses for accented relatives compared to unaccented relatives to the presence of the boundary before relative clauses containing a pitch accent (point 22). The question now is why listeners interpret the prosodic boundary in this manner. As noted previously, several earlier studies reported a similar finding: a boundary promotes high attachment of the phrase after the boundary. We suspect a strong boundary may signal high attachment of the following constituent because the boundary can legitimise the extra syntactic bracket required before a high-attached phrase. ${ }^{4}$

Our points (21) and (22) are thus in agreement with previous conclusions that a strong prosodic boundary is taken by listeners to indicate high attachment of the following constituent. Our points (18-20), however, go beyond previous conclusions. We do not agree with the suggestion of some previous investigators that prominence or focus does not syntactically disambiguate sentences (e.g. Price et al., 1991). The present results disconfirm such a claim by showing that, under some circumstances, disambiguation can be achieved through the placement of accent.

Thinking of how accent placement can be used to disambiguate sentences, however, may be misleading. It seems to suggest that a speaker consciously manipulates prosody to disambiguate sentences. We think that asking how a speaker can do this is not quite the right way of looking at the problem. We doubt that speakers are generally aware of the temporary ambiguities in the sentences they utter (at least before uttering them). Hence, looking at the problem in terms of what classes of syntactic ambiguities are disambiguated by boundaries, disambiguated by pitch accents, or not disambiguated at all, is to take a very external perspective on the problem. Presumably, speakers are simply trying to express themselves using the grammatical devices available to them, and listeners employ the grammar and other knowledge to discern the speaker's intent. Ambiguity resolution is probably most often just a by-product of these processes, and does not directly guide the processing operations of speaker or listener. ${ }^{5}$ If so, then the task is to

\footnotetext{
${ }^{4}$ The grammatical function of a prosodic boundary is to mark the edge of a phonological unit. These edges correspond to syntactic brackets, the edges of sense units, or both (Selkirk, 1984). By using a full prosodic representation, one can account for their distribution without claiming a one-to-one correlation between prosodic boundaries and syntactic boundaries. Thus, one can distinguish among prosodic boundaries inserted due to a narrowly contrastive phrase, as in (i); due to the weight of a phrase, as in (ii); or used as a reflection of high attachment, as in the ill-formed (iii), and also predict whether the sentence is prosodically well-formed or not.

i. When Mary was mending \% SOCKS \% they fell off her lap.

ii. When Mary was mending \% all those old torn socks \% fell off her lap.

iii. *When Mary was mending \% socks \% fell off her lap.

${ }^{5} \mathrm{~W}$ riting, of course, is different, since editing often goes on throughout the various stages of producing written text.
} 
understand how focus (as represented at various levels) and prosody (including pitch, duration, etc.) are manipulated in sentence processing in general, without any special attention to syntactic ambiguities.

We believe that our data can best be interpreted by assuming that listeners make use of a full prosodic representation during the early stages of parsing. Such a representation includes the pitch accents and minor prosodic boundaries discussed above, as well as the major prosodic boundaries considered in other work.

\section{REFERENCES}

Bartels, C., \& Kingston, J. (1994). Salient pitch cues in the perception of contrastive focus. In P. Bosch \& R.van der Sandt (Eds), Focus and natural language processing, Vol. 1: Intonation and syntax, pp.1-10. Working Papers of the IBM Institute for Logic and Linguistics. Heidelberg: IBM.

Beach, C.M. (1991). The interpretation of prosodic patterns at points of syntactic structure ambiguity: Evidence for cue trading relations. Journal of Memory and Language, 30, 644-663.

Beckman, M.E., \& Ayers, G.M. (1993). Guidelines for ToBI labeling. Unpublished manuscript, Ohio State University, Columbus, OH.

Beckman, M.E., \& Pierrehumbert, J.B. (1986). Intonational structure in Japanese and English. Phonology, 3, 255-309.

Bock, K., \& Mazella, J.R. (1983). Intonational marking of given and new information: Some consequences for comprehension. Memory and Cognition, 11, 64-76.

Bolinger, D. (1986). Intonation and its parts. Stanford, CA: Stanford University Press.

Broderick, K. (1995). Intonational phrasing and adjunct extraction. Unpublished manuscript, University of Massachusetts, Amherst, MA.

Clark, H.H., \& Haviland, S.E. (1977). Comprehension and the given-new contract. In R. Freedle (Ed.), Discourse comprehension and production, pp. 1-40. Norwood, NJ: Ablex.

Cooper, W., \& Sorensen, J. (1981). Fundamental frequency in speech production. New York: Springer-Verlag.

Cutler, A. (1976). Beyond parsing and lexical look-up: An enriched description of auditory comprehension. In R.T. Wales \& E.C.T. Walker (Eds), New approaches to language mechanisms, pp. 133-149. Amsterdam: North-Holland.

Cutler, A., \& Fodor, J.A. (1979). Semantic focus and sentence comprehension. Cognition, 7 , 49-59.

Cutler, A., \& Foss, D.J. (1977). On the role of sentence stress on sentence processing. Language and Speech, 20,1-10.

Eady, S.J., Cooper, W.E., Klouda, G.V., Mueller, P.R., \& Lotts, D.W. (1986). Acoustical characteristics of sentential focus: Narrow vs. broad and single $v s$. dual focus environments. Language and Speech, 29, 233-251.

Eefting, W. (1992). The effect of accentuation and word duration on the naturalness of speech. Journal of the Acoustical Society of America, 91, 411-420.

Ferreira, F. (1993). Creation of prosody during sentence production. Psychological Review, 100, 233-253.

Fodor, J.D., \& Inoue, A. (1994). The diagnosis and cure of garden paths. Journal of Psycholinguistic Research, 23, 405-432.

Fowler, C. (1988). Differential shortening of repeated content words produced in various communicative contexts. Language and Speech, 31, 307-319. 
Fowler, C., \& Housum, J. (1987). Talkers' signalling of "new" and "old" words in speech and listeners' perception and use of the distinction. Journal of Memory and Language, 26, 489-504.

Frazier, L. (1979). On comprehending sentences: Syntactic parsing strategies. Bloomington, IN: Indiana University Linguistics Club.

Frazier, L., \& Clifton, C., Jr (1995). Construal. Cambridge, MA: MIT Press.

Gibson, E. (1991). A computational theory of human linguistic processing: Memory limitations and processing breakdown. Unpublished $\mathrm{PhD}$ dissertation, Carnegie-Mellon University.

Gilboy, E., Sopena, J., Clifton, C.J., \& Frazier, L. (1995). Argument structure and association preferences in Spanish and English compound NPs. Cognition, 54, 131-167.

Gussenhoven, C., \& Rietveld, A.C.M. (1992). Intonation contours, prosodic structure, and pre-boundary lengthening. Journal of Phonetics, 20, 283-303.

Hornby, P.A. (1972). The psychological subject and predicate. Cognitive Psychology, 3, $632-642$.

Hornby, P.A. (1974). Surface structure and presupposition. Journal of Verbal Learning and Verbal Behavior, 13, 530-538.

Klatt, D. (1975). Vowel lengthening is syntactically determined in connected discourse. Journal of Phonetics, 3, 129-140.

Lehiste, I. (1973). Phonetic disambiguation of syntactic ambiguity. Glossa, 7, 107-122.

Lehiste, I. (1974). Suprasegmentals. Cambridge, MA: MIT Press.

Lieberman, P. (1967). Intonation, perception, and language. Cambridge, MA: MIT Press.

MacDonald, M., Pearlmutter, N., \& Seidenberg, M. (1994). The lexical nature of syntactic ambiguity resolution. Psychological Review, 101, 676-703.

Marcus, M., \& Hindle, D. (1990). Description theory and intonation boundaries. In G. Altmann (Ed.), Cognitive models of speech processing: Psycholinguistic and computational perspectives, pp. 483-512. Cambridge, MA: MIT Press.

Mitchell, D. (1994). Sentence parsing. In M. Gernsbacher (Ed.), Handbook of psycholinguistics, pp. 375-409. New York: Academic Press.

Nagel, H., Shapiro, L., \& Nawy, R. (1994). Prosody and the processing of filler-gap sentences. Journal of Psycholinguistic Research, 23, 473-486.

Nespor, M., \& Vogel, I. (1986). Prosodic phonology. Dordrecht: Foris.

Pierrehumbert, J.B. (1980). The phonology and phonetics of English intonation. PhD dissertation, MIT, Cambridge, MA.

Pierrehumbert, J.B., \& Hirschberg, J. (1990). The meaning of intonational contours in the interpretation of discourse. In P.R. Cohen, J. Morgan, \& M.E. Pollack (Eds), Intentions in communication, pp. 271-311. Cambridge, MA: MIT Press.

Price, P.J., Ostendorf, M., Shattuck-Hufnagel, S., \& Fong, C. (1991). The use of prosody in syntactic disambiguation. Journal of the Acoustical Society of America, 90, 2956-2970.

Pritchett, B. (1992). Grammatical competence and parsing performance. Chicago, IL: University of Chicago Press.

Selkirk, E. (1984). Phonology and syntax: The relation between sound and structure. Cambridge, MA: MIT Press.

Selkirk, E. (1995). Sentence prosody: Intonation, stress, and phrasing. In J. Goldsmith (Ed.), Handbook of phonological theory, pp. 550-569. Oxford: Basil Blackwell.

Slowiaczek, M.L. (1981). Prosodic units as language processing units. Unpublished doctoral dissertation, University of Massachusetts, Amherst, MA.

Speer, S.R., Crowder, R.G., \& Thomas, L.M. (1993). Prosodic structure and sentence recognition. Journal of Memory and Language, 32, 336-358.

Terken, J., \& Nooteboom, S.G. (1987). Opposite effects of accentuation and deaccentuation on verification latencies for Given and New information. Language and Cognitive Processes, 2, 145-164. 
Wales, R., \& Toner, H. (1979). Intonation and ambiguity. In W. Cooper \& E.C.T. Walker (Eds), Sentence processing: Psycholinguistic studies presented to Merrill Garrett. Hillsdale, NJ: Lawrence Erlbaum Associates Inc.

Warren, P. (1985). The temporal organization and perception of speech. $\mathrm{PhD}$ dissertation, Cambridge University, Cambridge.

Wightman, C.W., Shattuck-Hufnagel, S., Ostendorf, M., \& Price, P.J. (1992). Segmental durations in the vicinity of prosodic phrase boundaries. Journal of the Acoustical Society of America, 91, 1707-1717.

\section{APPENDIX 1}

\section{Materials used in Experiment 1}

\section{Relative clause sentences}

Four versions of each sentence: Choose one CAPITALISED word to accent, choose one preposition.

\section{Set A: Argument/adjunct sentences}

1. The sun sparkled on the PROPELLER of/near the PLANE that the mechanic was so carefully examining.

2. The squirrels raced through the LEAVES of/from the TREE that had recently fallen down.

3. The detective eyed the ENTRANCE of/near the HOUSE that showed clear signs of damage.

4. The plumber suggested we change the FAUCET of/behind the SINK that we finally installed last year.

5. Sylvia carefully examined the HANDLE of/on the POT that she had just finished repairing.

6. We already have to repair the TIRE of/for the BICYCLE that we bought yesterday.

7. In the meeting they showed us the LABEL of/on the BOTTLE that the artist agreed to design.

8. The insurance inspector photographed the COVER of/for the BOAT that was covered with graffiti.

\section{Set B: Pseudoargument/adjunct sentences}

9. The tourists admired the MUSEUM of/in the CITY that they visited again in August.

10. John smashed the CAR of/from the RENTAL-AGENCY that his wife hated so much.

11. All the men distrusted the MACHINES of/in the FACTORY that had accidentally been set on fire.

12. The Japanese were impressed by the INVESTMENTS of/from the AGENCIES that were making such large profits.

13. The magazine article failed to mention the LIBRARY of/near the ELEMENTARY SCHOOL that had just recently been built.

14. The local newspaper described the CEREMONIES of/in the CLUB that people seemed to find so ridiculous.

15. The architect designed the PLAYGROUND of/near the PARK that the children visited frequently.

16. The collector admired the FURNITURE of/in the DOLLHOUSE that had been carefully repainted. 


\section{APPENDIX 2}

Percentages of response choices made in Experiment 1

\begin{tabular}{|c|c|c|c|c|c|c|c|c|}
\hline \multirow{2}{*}{$\begin{array}{l}\text { Accent } \\
\text { Location }\end{array}$} & \multirow[b]{2}{*}{ Set } & \multirow[b]{2}{*}{ Sentence Preposition } & \multirow[b]{2}{*}{ Splicing } & \multicolumn{5}{|c|}{ Response Choice } \\
\hline & & & & $N P_{1}$ & $N P_{1} P R E P N P_{2}$ & "High" & $\mathrm{NP}_{2}$ & Other \\
\hline $\mathrm{NP}_{1}$ & Set 1 & "of" & Normal & 21 & 45 & 66 & 27 & 6 \\
\hline $\mathrm{NP}_{1}$ & Set 1 & "of" & Cross & 15 & 46 & 61 & 35 & 4 \\
\hline $\mathrm{NP}_{1}$ & Set 1 & non-"of" & Normal & 17 & 54 & 71 & 19 & 10 \\
\hline $\mathrm{NP}_{1}$ & Set 1 & non-"of" & Cross & 23 & 38 & 61 & 31 & 8 \\
\hline $\mathrm{NP}_{1}$ & Set 2 & "of" & Normal & 27 & 21 & 48 & 42 & 10 \\
\hline $\mathrm{NP}_{1}$ & Set 2 & "of" & Cross & 29 & 23 & 52 & 35 & 13 \\
\hline $\mathrm{NP}_{1}$ & Set 2 & non-"of" & Normal & 50 & 15 & 65 & 29 & 6 \\
\hline $\mathrm{NP}_{1}$ & Set 2 & non-"of" & Cross & 33 & 29 & 62 & 29 & 8 \\
\hline $\mathrm{NP}_{2}$ & Set 1 & "of" & Normal & 10 & 25 & 35 & 48 & 17 \\
\hline $\mathrm{NP}_{2}$ & Set 1 & "of" & Cross & 13 & 29 & 42 & 50 & 8 \\
\hline $\mathrm{NP}_{2}$ & Set 1 & non-"of" & Normal & 17 & 31 & 48 & 48 & 4 \\
\hline $\mathrm{NP}_{2}$ & Set 1 & non-"of" & Cross & 33 & 23 & 56 & 29 & 15 \\
\hline $\mathrm{NP}_{2}$ & Set 2 & "of" & Normal & 27 & 10 & 37 & 54 & 8 \\
\hline $\mathrm{NP}_{2}$ & Set 2 & "of" & Cross & 29 & 19 & 48 & 38 & 15 \\
\hline $\mathrm{NP}_{2}$ & Set 2 & non-"of" & Normal & 38 & 21 & 59 & 31 & 10 \\
\hline $\mathrm{NP}_{2}$ & Set 2 & non-"of" & Cross & 42 & 21 & 63 & 33 & 4 \\
\hline
\end{tabular}

Note: "High" is the sum of $\mathrm{NP}_{1}$ and $\mathrm{NP}_{1} \mathrm{PREPNP}_{2}$.

Interactions not reported in the text:

Normal/cross-spliced $\times \mathrm{NP}_{1} / \mathrm{NP}_{2}$ accent: $F_{1}(1,47)=3.04,0.10>P>0.05 ; \quad F_{2}(1,14)=4.73$, $P<0.05$.

Normal/cross-spliced $\times$ of/non-of $\times$ Set $1 /$ Set $2: F_{1}(1,47)=1.83, P>0.15 ; F_{2}(1,14)=7.00$, $P<0.01$.

Normal/cross-spliced $\times$ of/non-of $\times$ Set $1 /$ Set $2 \times \mathrm{NP}_{1} / \mathrm{NP}_{2}$ accent: $F_{1}(1,47)=1.77, P>0.15$; $F_{2}(1,14)=5.72, P<0.05$.

\section{APPENDIX 3}

\section{Materials used in Experiment 2}

Four versions of each sentence, formed by placing focal $v s$ contrastive accent on first underlined word and by placing accent or no accent on second underlined word.

1. The reporter recently interviewed the sister of the senator who was so controversial.

2. George questioned the brother of the minister who was divorced.

3. Hank had built the drum machine of the band that disappeared.

4. Larry stared at the arm of the mannequin that needed paint.

5. Lloyd pondered the map of the pyramid that was incomplete.

6. Stacey wanted to invite the friend of the secretary who was German.

7. Janice kicked the speaker of the stereo that sometimes didn't work.

8. Susan was dating the cousin of the artist who was a veteran.

9. Alice was listening to the chirping of the bird that was unusually pretty.

10. Phil mended the sleeve of the shirt that was stained.

11. On Saturday, Carol hiked the trail of the park that was crowded. 
12. Yesterday Lisa photographed the museum of the city that was in the news.

13. The cops found the hubcap of the car that was stolen.

14. The Board of Health contacted the restaurant of the hotel that was infested.

15. Jennifer was blackmailing the boss of the clerk who was dishonest.

16. Stan waited impatiently in the checkout lane of the supermarket that had just opened up. 